Check for updates

Cite this: RSC Adv., 2017, 7, 23176

Received 18th January 2017

Accepted 7th April 2017

DOI: $10.1039 / c 7 r a 00775 b$

rsc.li/rsc-advances

\section{Laser sintering and post-processing of a walnut shell/Co-PES composite}

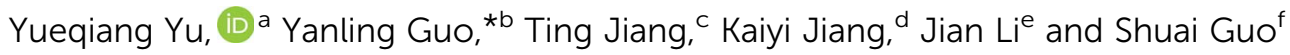

In order to recycle agricultural and forestry waste and reduce the cost of materials, energy consumption and $\mathrm{CO}_{2}$ emission of the laser sintering process, herein, a sustainable and low-cost walnut shell/Co-PES composite (WSPC) is developed as a feedstock for laser sintering technology. Laser sintering experiments are performed to study the formability of WSPC. Through single layer sintering, the optimal mixture ratio of walnut shell powder and Co-PES was determined, which is $1: 4$ by weight. Moreover, the microstructure and dispersity of walnut shell particles in the WSPC prototype were examined via scanning electron microscopy (SEM). In addition, it is shown that the WSPC parts have good forming accuracy and mechanical properties. The tensile strength, bending strength and impact strength of the WSPC parts are $6.0801 \mathrm{MPa}$, 9.6759 MPa and $0.8102 \mathrm{~kJ} \mathrm{~m}^{-2}$, respectively. In order to improve the strength of the WSPC parts, their internal pores were filled with infiltrating wax through post-processing. The result shows that the density of the WSPC parts considerably increases and their average tensile strength, bending strength and impact strength increase to $6.5879 \mathrm{MPa}, 11.0822 \mathrm{MPa}$ and $0.9504 \mathrm{~kJ} \mathrm{~m}^{-2}$, respectively.

\section{Introduction}

Additive manufacturing (AM) technology is a modern technology that combines CAD/CAM, CNC, lasers, and materials science. This technology could be used to create $3 \mathrm{D}$ parts directly from a CAD model based on the principle of discrete accumulation. Selective laser sintering (SLS) is an AM technology, which was reported by C. R. Deckard ${ }^{\mathbf{1}}$ in his doctoral thesis at the University of Texas at Austin in 1988. Different from other AM technologies, there is a wide material selection, no support is needed during manufacturing, and unsintered materials could be recycled and reused. Parts fabricated via SLS have high precision and mechanical properties. Therefore, SLS has been widely applied in industries such as the automotive, aerospace, casting parts, medical treatment, and construction industries. ${ }^{2,3}$

At present, the development of materials for SLS is mainly focused on metals, ceramics, polymers and their corresponding composites. $^{\mathbf{4 - 1 0}}$ However, material preparation technology is still

${ }^{a}$ Northeast Forestry University, College of Mechanical and Electrical Engineering, Harbin, 150040, China

${ }^{b}$ Northeast Forestry University, College of Mechanical and Electrical Engineering, Harbin, 150040, China. E-mail: nefugyl@hotmail.com

${ }^{c}$ Harbin University of Science and Technology, School of Mechanical Engineering, Harbin, 150080, China

${ }^{d}$ Northeast Forestry University, College of Engineering and Technology, Harbin, 150040, China

${ }^{e}$ Northeast Forestry University, College of Mechanical and Electrical Engineering, Harbin, 150040, China

${ }^{f}$ Northeast Forestry University, College of Mechanical and Electrical Engineering, Harbin, 150040, China commercially guarded and very expensive, which restrict the development and application of SLS. Therefore, there is an urgent need to develop new natural and environmentally friendly materials with low cost, energy consumption and $\mathrm{CO}_{2}$ emission for SLS. Professor Yanling Guo from Northeast Forestry University first proposed the use of natural and cheap forestry waste as feedstock for SLS to reduce its material cost and environmental influence. Previous research mainly focused on sintered wood-plastic composites (WPC) ${ }^{\mathbf{1 1 - 1 3}}$ and rice husk powder/Co-PES (RHPC), ${ }^{\mathbf{1 4}}$ from which good results were obtained. However, different biomass powders have different geometric distributions and physical and chemical properties, and these properties directly affect the laser forming performance of composites. Compared to eucalyptus wood powder and rice husk powder, walnut shell powder is a substantial waste source, and it is easy to crush and has unique advantages such as adsorption. In addition, walnut shell particles are spherical, which is advantageous for powder spreading, and flat, smooth and dense layers, which are the basis for the production of prototypes with high precision and strength.

Based on the advantages of walnut shell powder, herein, it is chosen as the structural material added to the Co-PES matrix for the development of a walnut shell plastic composite (WSPC) as a feedstock for SLS. The sintering property of WSPC is studied in depth.

\section{Experimental}

\subsection{Material preparation}

Walnut shell powder and hot melt plastic powder are the main ingredients of WSPC that account for more than $90 \%$ of the 
Table 1 Properties of main the ingredients of WSPC

\begin{tabular}{lll}
\hline Property & $\begin{array}{l}\text { Walnut shell } \\
\text { powder }\end{array}$ & $\begin{array}{l}\text { Co-PES } \\
\text { powder }\end{array}$ \\
\hline Particle diameter range $(\mu \mathrm{m})$ & $0-96$ & $0-58$ \\
Particle shape & Irregular & Irregular \\
Packing density $\left(\mathrm{g} \mathrm{cm}^{-3}\right)$ & 0.48 & 0.7 \\
Melt index $(\mathrm{g} / 10 \mathrm{~min} @ 160$ & - & 30 \\
$\left.{ }^{\circ} \mathrm{C}\right)$ & - & 350 \\
Viscosity $\left(\mathrm{Pa} \mathrm{s@160}{ }^{\circ} \mathrm{C}\right)$ & &
\end{tabular}

Table 2 Specific formulas of walnut shell powder and Co-PES

\begin{tabular}{lll}
\hline Serial number & Walnut shell powder & Co-PES powder \\
\hline I & 1 & 1 \\
II & 1 & 2 \\
III & 1 & 2.5 \\
IV & 1 & 4 \\
V & 0 & 1
\end{tabular}

total mass of the composite material. In addition, there is a small amount of light stabilizers, lubricants, and other auxiliary reagents, which help to improve the material's sintering performance and properties of the sintered part. The walnut shell used in the experiments was derived from the waste of walnut deep processing enterprises. After degreasing, crushing, filtering and other processing techniques, superficial microporous walnut shell particles were obtained. Hot melt glue powder, which is a common polyester hot melt adhesive (Co-PES), was provided by Shanghai Tian Nian Materials Technology Ltd. Some properties of the main ingredients of WSPC are shown in Table 1.

Before the walnut shell powder was mixed with Co-PES it was dehydrated for $3.5 \mathrm{~h}$ in a Beijing Long Yuan Technology Ltd. incubator at a temperature of $105{ }^{\circ} \mathrm{C}$. During dehydration, the powder was weighed at $1 \mathrm{~h}$ intervals until the mass was constant. Then, the dried walnut shell powder was mixed with Co-PES according to specific formulas (shown in Table 2) using an SHR50A high-speed mixer from Zhangjiagang Hongji Machinery Ltd. In order to obtain maximum particle dispersion, a small amount of auxiliary additive was added during the mixing process. The powder mixture was mixed for $15 \mathrm{~min}$ at a temperature below $30{ }^{\circ} \mathrm{C}$ at low-speed and then $5 \mathrm{~min}$ at highspeed. The mixed powder was taken out from the high-speed mixer and cooled naturally to obtain WSPC.

\subsection{Single layer sintering experiment}

Before the laser sintering experiment for the WSPC powder, a single layer sintering experiment was initially performed to efficiently determine the feasibility of using the WSPC powder and good ratio of the two main components. According to the designed mixture ratios shown in Table 2, four WSPC and CoPES samples were prepared using different mixture ratios. Each powder mixture was deposited on a plate manually to create a flat and even surface. The dish was then placed in the middle of the part bed in an AFS-360 sinter station obtained from Beijing Long Yuan. Based on previous experience of sintering Co-PES, the laser power was set at $10 \mathrm{~W}$. The formula with the optimal content of walnut shell powder feasible for laser sintering was selected, and raw materials were prepared for the subsequent laser sintering experiments and testing.

\subsection{Differential scanning calorimetry (DSC)}

The glass-transition temperature of the Co-PES and WSPC powder was analyzed using an American Pyris Diamond differential scanning calorimeter. The testing parameters were as follows: amount of WSPC sample was $5 \mathrm{mg}$, heating rate was $10{ }^{\circ} \mathrm{C} \min ^{-1}$, and the testing temperature range was $40-200{ }^{\circ} \mathrm{C}$. Finally, DSC curves of the Co-PES powder and WSPC powder were obtained.

\subsection{Laser sintering experiment}

Fabrication of WSPC parts and sintering processing were conducted on an AFS-360 rapid prototype manufacturing instrument produced by Beijing Long Yuan. The main processing parameters were as follows: scanning speed of $2000 \mathrm{~mm} \mathrm{~s}^{-1}$, scanning interval of $0.2 \mathrm{~mm}$, layering thickness of $0.15 \mathrm{~mm}$, and laser powers as shown in Table 3.

\subsection{Post-processing technology}

After the sintered WSPC parts were removed from the sinter station they were preserved in a Beijing Long Yuan Technology Ltd. incubator at a temperature of $60{ }^{\circ} \mathrm{C}$ for $30 \mathrm{~min}$. Stearic acid was melted with industrial wax in a $1: 1$ ratio in a permeable Beijing Long Yuan Technology Ltd wax machine and heated to $70{ }^{\circ} \mathrm{C}$. When the temperature was constant, the part was slowly immersed in the melted mixed liquor using a hook, with an immersion time of about 5-10 s and then slowly removed and placed on filter paper to absorb the excess liquor on the surface of the part. Then it was left to cool at room temperature.

\subsection{Mechanical testing}

Mechanical testing was performed on a CMT5504 testing machine from TMS System Company and a TCJ-4 impact touching screen testing machine with simply a supported beam produced by the Tai He Testing Machine Limited, Jilin Province. The test standards are as follows:

Tensile strength was tested according to the ISO527-2 Standard, crosshead speed was $5 \mathrm{~mm} \mathrm{~min}^{-1}$, and the gauge length was $50 \mathrm{~mm}$.

Flexural strength was tested under three-point bending according to the ISO178 Standard. Crosshead speed was $0.1 \mathrm{~mm}$ $\min ^{-1}$, and span length was $64 \mathrm{~mm}$.

Table 3 Laser power used to sinter WSPC powder

\begin{tabular}{lllllll}
\hline Serial number & 1 & 2 & 3 & 4 & 5 & 6 \\
Laser power (W) & 6.6 & 7.7 & 8.8 & 9.9 & 11 & 12 \\
Serial number & 7 & 8 & 9 & 10 & 11 & 12 \\
Laser power (W) & 14 & 16 & 18 & 20 & 22 & 23
\end{tabular}


Unnotched impact strength was tested according to the ISO179-2 Standard. Pendulum impact energy was $4 \mathrm{~J}$, and span length was $60 \mathrm{~mm}$.

\subsection{Microstructure characterization}

Since the materials were non-conductive, the specimens were first sputtered with gold using SEM specimen coating equipment. An FEI Quanta200 electronic scanning microscope produced by the Dutch company was used to observe and obtain images of the microstructures of the walnut shell powder, CoPES powder, WSPC powder, and cross sections of the sintered WSPC part before and after post processing.

\section{Results and discussion}

\subsection{Single layer sintering}

A single layer sintering experiment was initially performed to study the formability of WSPC, prepared using different mixing ratios, and determine a suitable formula for the subsequent experiments. Using the premixed powder, four single layer scans were conducted under constant processing conditions (laser power of $6.6 \mathrm{~W}$, scanning speed of $2000 \mathrm{~mm} \mathrm{~s}^{-1}$, scanning interval of $0.2 \mathrm{~mm}$, layering thickness of $0.15 \mathrm{~mm}$, powder preheating temperature of $85^{\circ} \mathrm{C}$, and processing temperature of $75^{\circ} \mathrm{C}$ ). As shown in Fig. 1, with an increase in Co-PES content, the strength of the single layer improved. Fig. 1(a) indicates that the amount of Co-PES ( $50 \%$ by mass) is not enough to bind an equal amount of walnut shell powder; thus the layer is out of shape and the large amount of walnut shell powder, which is dark in color, made the layer appear light black.

Fig. 1(b)-(e) show the results when the amount of Co-PES was increased to more than $67 \%$. The four single layers are sintered moldings. However, the images in Fig. 1(b) and (c) show that the sintered layers are fragile. In Fig. 1(e), the sintered layer has a high bonding strength but the single test specimen is severely ductile,

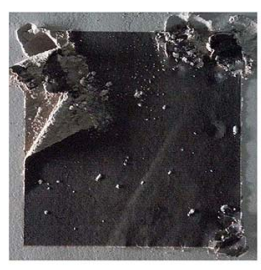

(a) Ratio I

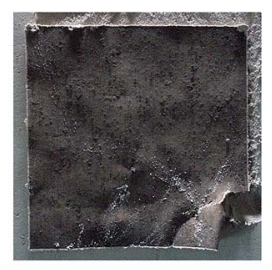

(b) Ratio II

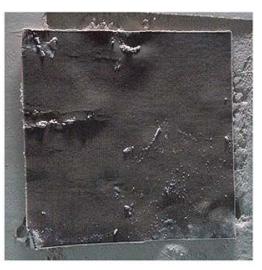

(c) Ratio III

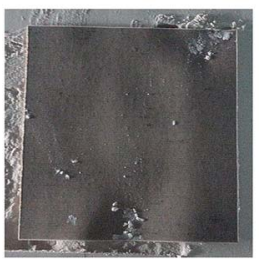

(d) Ratio IV

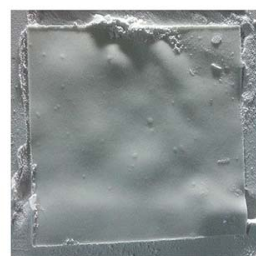

(e) Ratio V
Fig. 1 Single layer sintered WSPC and Co-PES samples prepared using different mass ratios of walnut shell powder and Co-PES. which results in bad shape precision, compared to Fig. 1(b)-(d). Fig. 1(d) shows the single laser sintered layer of walnut shell powder and Co-PES in a mass ratio of $1: 4$, which presents good mechanical properties and forming accuracy. The surface is smooth and has a good apparent density. Therefore, walnut shell powder and Co-PES in the ratio of $1: 4$ is optimal. The formation effect is good and the content of walnut shell powder is relatively high. Thus, walnut shell powder and Co-PES in the ratio of $1: 4$ were used in the SLS experiment.

\subsection{Morphology characterization of WSPC powder}

Fig. 2 shows the microtopographies of neat walnut shell powder, neat Co-PES powder and the WSPC composite. As shown in Fig. 2(a), the shape of the walnut shell particles is irregular and their surface is very rough. Fig. 2(b) shows that the Co-PES powder particles are irregular and bigger than the walnut shell particles, and the angular Co-PES particles have a smooth surface and their particle size is non-uniform. Fig. 2(c) shows that the distribution of walnut shell and Co-PES particles in the composite in a mass ratio of $1: 4$ is uniform and there is no agglomeration.

\subsection{Sintering temperature of WSPC powder}

SLS is a process that mainly utilizes the thermal effect; however, walnut powder has no melting point and Co-PES is an amorphous polymer; thus the heating and cooling of Co-PES play an important role in their formation. The glass transition temperature of Co-PES and WSPC was obtained through DSC, and then the preheating and processing temperatures during sintering were determined accordingly. During laser sintering, the feasible processing temperature range is called the sintering window. Generally, a wide sintering window could guarantee the feasibility of using the material as a feedstock for laser sintering and obtaining a high forming accuracy of sintered parts.

In order to prevent laser sintered parts from warping in the process of sintering, SLS powder materials are preheated within

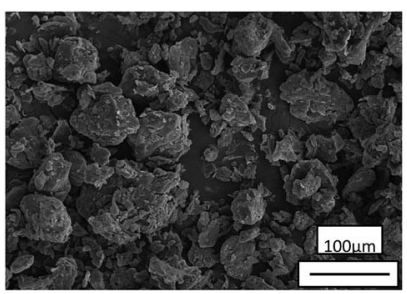

(a) Walnut shell powder

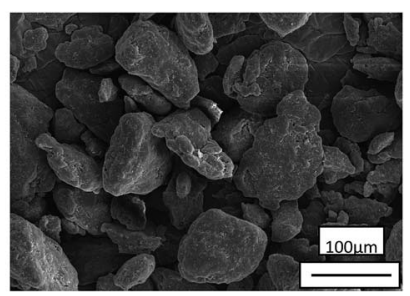

(b) Co-PES powder

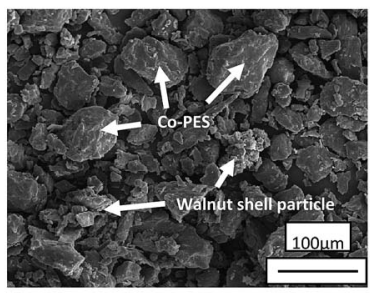

(c) WSPC powde

Fig. 2 SEM images of walnut shell, Co-PES and WSPC powders. 


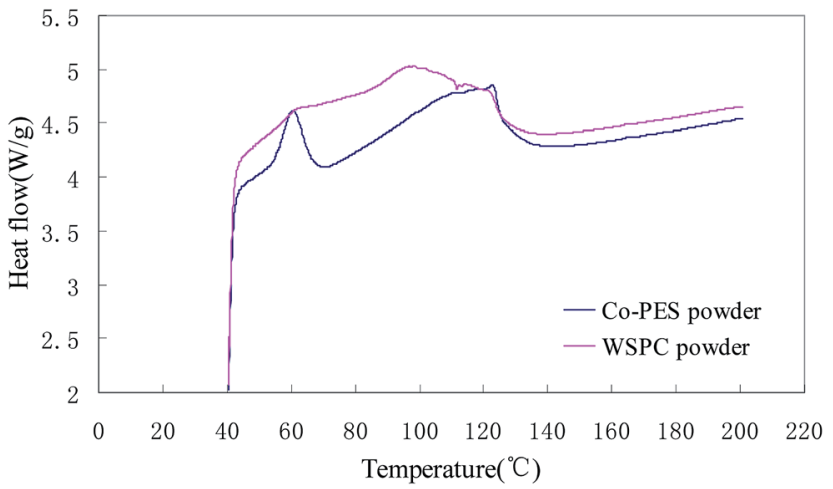

Fig. 3 DSC curves of Co-PES and WSPC powders.

a specific temperature range. The temperature range is called sintering window presented as $\left[T_{\mathrm{s}}, T_{\mathrm{c}}\right] . T_{\mathrm{s}}$ is the softening point, and $T_{\mathrm{c}}$ is the caking temperature. Since Co-PES is a noncrystallizable polymer, $T_{\mathrm{s}}$ is the glass transition temperature $\left(T_{\mathrm{g}}\right)$ of Co-PES and WSPC. $T_{\mathrm{c}}$ could not be obtained from the DSC curves, and it was only observed by experiment. The DSC curves of the Co-PES and WSPC powders are shown in Fig. 3, in which their $T_{\mathrm{g}}$ are $57.48{ }^{\circ} \mathrm{C}$ and $60.3{ }^{\circ} \mathrm{C}$. It can be observed from the experiments that Co-PES and WSPC were completely coking at $92{ }^{\circ} \mathrm{C}$ and $99{ }^{\circ} \mathrm{C}$, respectively. The sintering windows of Co-PES and WSPC are 57.48-92 ${ }^{\circ} \mathrm{C}$ and $60.3-99{ }^{\circ} \mathrm{C}$, respectively. Thus, the preheating temperatures of Co-PES and WSPC should be controlled within these temperature ranges. During sintering the part bed displays a heat accumulation phenomenon. Thus, during sintering, the preheating temperature and part bed temperature of Co-PES and WSPC were $85^{\circ} \mathrm{C}$ and $75^{\circ} \mathrm{C}$, respectively.

\subsection{Laser sintering experiment}

In the process of laser sintering, the WSPC powder shows good mobility and formability and its sintered parts have a good forming accuracy. Two demonstration parts are shown in Fig. 4, in which their surfaces are brown and smooth, and their outlines are clearly visible. However, the mechanical strength of the formed parts is weak. Therefore, the WSPC demonstration parts were only used in the product samples and medical model.

\subsection{Post processing}

There was no pressure forced onto WSPC in the SLS process, and the WSPS parts accumulated using the powder. The

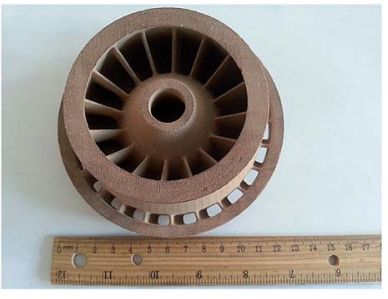

(a) Impeller

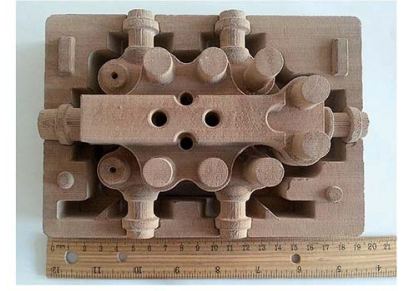

(b) Mandrel

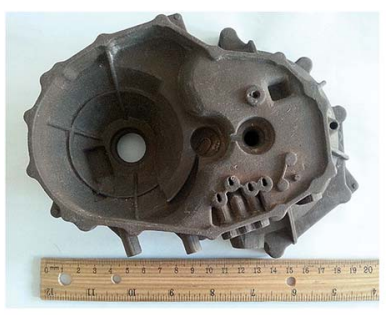

(a) Outside of the chassis

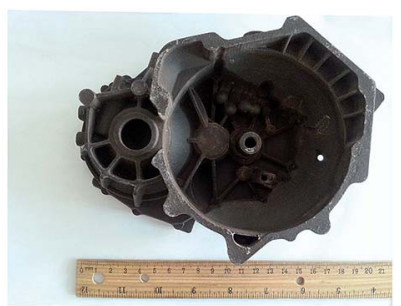

(b) Inside of the chassis
Fig. 5 WSPC demonstration part after post-processing.

viscosity of the melting Co-PES increased due to the addition of the walnut shell particles, and thus the surface and inside of the WSPC parts were porous. Therefore, compared to the Co-PES parts, the strength and density of the WSPC parts are low. In order to overcome this deficiency, post-processing using penetrating wax was conducted to fill the inner pores of the parts and increase their strength. This could also prevent the expansion and fragmentation of the WSPC parts caused by absorbing the moisture from air. The WSPC part after post processing is shown in Fig. 5. The dimensions of the WSPC parts in the $X, Y$ and $Z$ directions increase slightly due to the redundant wax coated on their surfaces after post processing. Moreover, polishing can be used to improve not only the dimensional accuracy, but also the surface quality. After polishing the WSPC parts, they could be used as a wood pattern and investment cast.

\subsection{Microstructure characterization}

The interfacial bonding mechanism of the organic walnut shell fillers and amorphous Co-PES matrix and the particles dispersibility play an important role in the mechanical properties of the laser sintered WSPC parts. As discussed above, laser power is the main energy source used to melt Co-PES and bond all the ingredients; therefore laser power is a main factor that affects the interfacial bonding force between the ingredients in WSPC. Using scanning electron microscopy, the microstructures of cross-sections of the WSPC parts sintered under different laser powers were observed, as shown in Fig. 6. It can be seen that the walnut shell particles are dispersed evenly in the Co-PES matrix and there is no agglomeration.

Fig. 6(a) shows the cross-section of the WSPC part sintered under a laser power of 7.7 W. Only some small sintering necks and a few large continuous Co-PES phase wrapping walnut shell particles could be found, and there is extensive interparticle porosity. Some uncoated smaller walnut shell particles just adhere to the surface of the continuous phase. These results indicate that the laser power of $7.7 \mathrm{~W}$ is not enough for Co-PES to melt sufficiently and obtain low viscosity to bond the surrounding walnut shell particles, which results in a weak interfacial bonding force in the WSPC parts.

In order to cohere the Co-PES particles and walnut shell particles completely, the laser power was increased to $11 \mathrm{~W}$. The cross-sections of the WSPC sintered parts are shown in Fig. 6(b), in which there are less holes and loose powder inside the WSPC

Fig. 4 WSPC demonstration parts. 


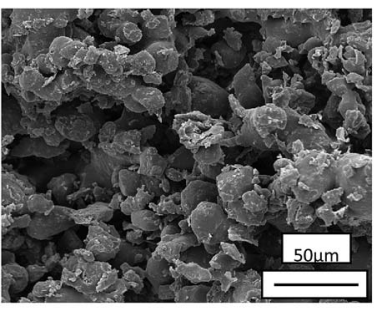

(a) 7.7 W laser power

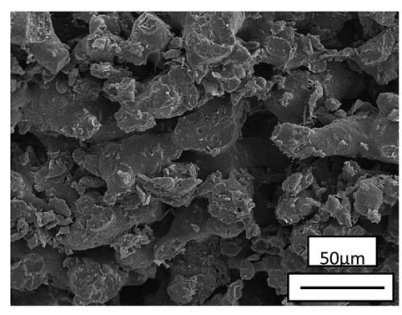

(b) $11 \mathrm{~W}$ laser power
Fig. 6 SEM photos of the cross-sections of the WSPC part magnified by 500 .

parts. Compared with Fig. 6(a), it can be found that due to the higher energy input, the Co-PES powder completely melted and generated a larger Co-PES continuous matrix, which made the structure denser, thus increasing the bonding area and sintering neck. Loose particles can be barely seen in the SEM image, and the porosity is reduced significantly. As a result, the mechanical properties were improved.

Fig. 7 shows the SEM photographs of the cross-sections of the WSPC parts after post processing with a laser power of $11 \mathrm{~W}$. It can be seen that all the internal pores are filled with wax, and hence the cross section becomes very dense and smooth. This indicates that all the walnut shell particles, Co-PES powder particles and wax are connected. In addition, the density and mechanical properties of the WSPC parts increased significantly.

\subsection{Mechanical property analysis}

Fig. 8 show the change curves of the tensile strength, flexural strength and impact strength of the sintered Co-PES parts, WSPC parts and WSPC parts after post-processing with a change in laser power, respectively.

As shown in Fig. 8, with an increase in laser power, the tensile strength and bending strength of the Co-PES parts first increase and reach the maximum of $12.0751 \mathrm{MPa}$ and $20.245 \mathrm{MPa}$ at the laser power of $20 \mathrm{~W}$, respectively, and then decrease; this impacts the strength of the Co-PES parts where it increases to the maximum value of $1.5089 \mathrm{~kJ} \mathrm{~m}^{-2}$ at the laser power of $18 \mathrm{~W}$ and then declines because of thermal decomposition. However, the tensile strength, bending strength and impact strength of the sintered WSPC parts increase to the maximum of $6.0801 \mathrm{MPa}$,

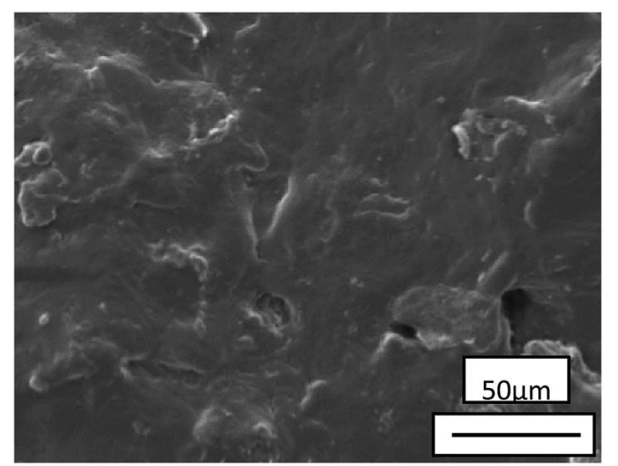

Fig. 7 SEM photo of the cross-section of the WSPC laser sintered part after post-processing magnified by 500 .
9.6759 $\mathrm{MPa}$ and $0.8102 \mathrm{~kJ} \mathrm{~m}^{-2}$, respectively, at the laser power of $22 \mathrm{~W}$. This is mainly because the increase in laser power improves the input energy density, which causes Co-PES to completely melt with low viscosity and high capillarity. Thus, it not only coheres itself, but also wraps the walnut shell powder tightly, which can improve the mechanical properties of the sintered Co-PES parts and WSPC parts. In particular, pure Co-PES was oversintered and decomposed, which caused a decrease in mechanical properties. However, the addition of walnut shell powder could keep Co-PES from absorbing too much laser energy. Thus, the mechanical properties of the sintered WSPC parts increase to a great extent when the laser power is below $22 \mathrm{~W}$. When the laser power is above $23 \mathrm{~W}$, the excessive energy input burns the powder and stops the process.
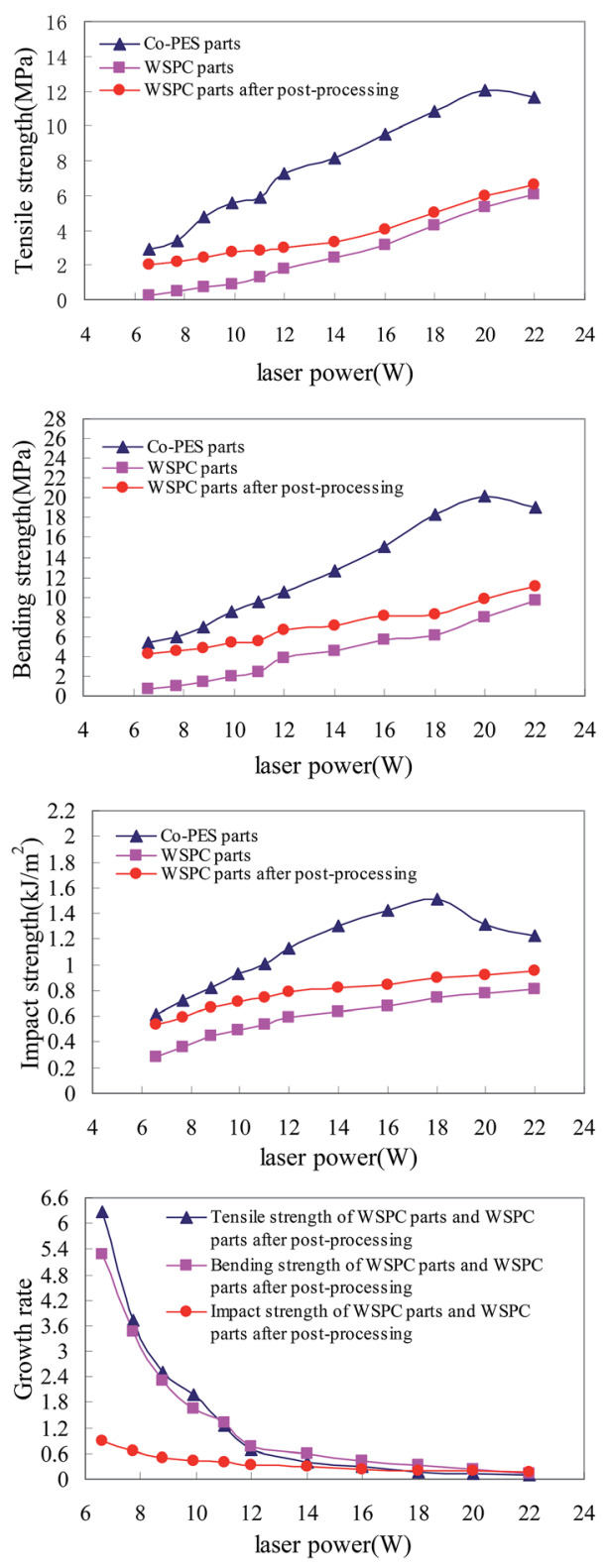

Fig. 8 Change curves of mechanical properties and growth rate of Co-PES parts, WSPC parts and WSPC parts after post-processing with the change in laser power. 
The mechanical properties of the WSPC parts are considerably improved after processing, as shown in Fig. 8. This is mainly because the melting industrial wax penetrates the WSPC parts and fills plenty of their internal pores, which makes them denser and thus improves their mechanical properties. It should be noted from the figures that post processing has a greater effect on the mechanical properties of the WSPC parts when the laser power is low. When the laser power reaches 6.6 W, the green WSPC parts have poor strength, and post processing increases their tensile strength and bending strength by 7 times and impact strength by one time. However, the growth rate drops considerably with the increase in the laser powder. Its change curve is shown in Fig. 8.

\section{Conclusions}

Herein, we successfully developed a walnut shell/Co-PES composite and used it as a feedstock for laser sintering technology. It is a natural, environmentally friendly and low-cost material that has good formability in laser sintering. Moreover, the sintered WSPC parts have relatively high forming accuracy and mechanical properties.

A single layer sintering experiment was performed, which verified the feasibility of using WSPC as a feedstock for SLS. The optimal formation effect of WSPC was obtained when the ratio of walnut shell powder and Co-PES was $1: 4$ by mass.

The DSC curves of the Co-PES powder and WSPC powder were obtained by differential scanning calorimetry. The glass transition temperatures of Co-PES and WSPC were $57.48{ }^{\circ} \mathrm{C}$ and $60.3{ }^{\circ} \mathrm{C}$, respectively. It was experimentally observed that the coking temperatures of Co-PES and WSPC are $92{ }^{\circ} \mathrm{C}$ and $99{ }^{\circ} \mathrm{C}$, respectively. The sintering windows of Co-PES and WSPC are 57.48-92 ${ }^{\circ} \mathrm{C}$ and $60.3-99{ }^{\circ} \mathrm{C}$, respectively; thus, their preheating temperatures should be controlled within these temperature ranges. During sintering the part bed displays a heat accumulation phenomenon. Thus, during sintering, the preheating temperature and part bed temperature of Co-PES and WSPC were $85^{\circ} \mathrm{C}$ and $75^{\circ} \mathrm{C}$, respectively.

The tensile strength and bending strength of the Co-PES parts increased from 2.9001 $\mathrm{MPa}$ and 5.4566 MPa at a laser power of $6.6 \mathrm{~W}$ to the maximum of $12.0751 \mathrm{MPa}$ and $20.245 \mathrm{MPa}$ at a laser power of $20 \mathrm{~W}$ and then declined because of thermal decomposition. The maximum impact strength of the Co-PES parts was $1.5089 \mathrm{~kJ} \mathrm{~m}^{-2}$, which emerged at the laser power of $18 \mathrm{~W}$. The tensile strength, bending strength and impact strength of the WSPC parts constantly increased with an increase in laser power, with maximum values of $6.0801 \mathrm{MPa}$, 9.6759 $\mathrm{MPa}$ and $0.8102 \mathrm{~kJ} \mathrm{~m}^{-2}$, respectively. After processing with infiltrating wax, the tensile strength, bending strength and impact strength of the WSPC parts improved to $6.5879 \mathrm{MPa}$, $11.0822 \mathrm{MPa}$ and $0.9504 \mathrm{~kJ} \mathrm{~m}^{-2}$, respectively.

The microstructures of the walnut shell powder, Co-PES powder and WSPC powder and cross-sections of the microstructure of the WSPC parts before and after post-processing were characterized via SEM. The results show that the walnut shell particles were dispersed evenly in the WSPC powder and laser sintered parts and there was no agglomeration. When the laser power was $11 \mathrm{~W}$, the Co-PES powder fully melted and wet the walnut shell particles and formed a large continuous phase to provide the parts with good strength. Although the density of the WSPC parts increased consistently with an increase in laser power, their internal structure was still porous. After postprocessing with infiltrating wax, all their pores were filled with wax, and their cross sections became dense and uniform. This could explain why the mechanical properties of the WSPC parts were improved significantly after post processing.

In conclusion, laser sintering using the WSPC/Co-PES composite shows that it is feasible to use mixtures of low-cost, environmentally friendly and sustainable walnut shell powder and Co-PES as a feedstock for SLS to develop prototypes with good forming accuracy and mechanical properties.

\section{Acknowledgements}

This study was supported by the National Natural Science Foundation of China (51475089), the Basic Research Funds of the Central University (2572015AB12) and the Doctoral Special Fund (20130062110006).

\section{References}

1 C. R. Deckard, Selective Laser Sintering, PhD. Dissertation, The University of Texas at Austin, 1988.

2 J. Zhao, J. Sun, B. Ou, L. Jiang and T. Pei, Mould Industry, 2015, 41, 1.

3 F. Mangano, M. Bazzoli, L. Tettamanti, D. Farronato, M. Maineri, A. Macchi and C. Mangano, Lasers Med. Sci., 2013, 28, 5 .

4 G. I. Gheorghe, L. L. Badita, N. D. Ciobota and V. Despa, Dig. J. Nanomater. Bios., 2013, 8, 3.

5 T. Gustmann, A. Neves, U. Kühn, P. Gargarella, C. S. Kiminami, C. Bolfarini, J. Eckert and S. Pauly, Addit. Manuf., 2016, 11, 7.

6 T. J. Gill and K. K. B. Hon, Proc. Inst. Mech. Eng., Part B, 2004, 218, 10.

7 K. Shahzad, J. Deckers, Z. Y. Zhang, J. P. Kruth and J. Vleugels, J. Eur. Ceram. Soc., 2014, 34, 1.

8 Y. Shi, K. Liu, C. Li, Q. Wei, J. Liu and S. Xia, Journal of Mechanical Engineering, 2014, 50, 12.

9 K. Shahzad, J. Deckers, S. Boury, B. Neirinck, J. P. Kruth and J. Vleugels, Ceram. Int., 2012, 38, 2.

10 R. Velu and S. Singamneni, J. Mater. Res., 2014, 29, 17.

11 Y. Guo, K. Jiang, Z. Yu, Z. Xin and W. Zeng, J. Shanghai Jiaotong Univ., 2011, 45, 9.

12 Y. Guo, W. Zeng and K. Jiang, Dig. J. Nanomater. Bios., 2011, 6, 3.

13 W. Zeng, Y. Guo, K. Jiang, Z. Yu, Y. Liu, Y. Shen, J. Deng and P. Wang, J. Thermoplast. Compos. Mater., 2012, 26, 1.

14 W. Zeng, Y. Guo, K. Jiang, Z. Yua and Y. Liu, Dig. J. Nanomater. Bios., 2012, 7, 3. 